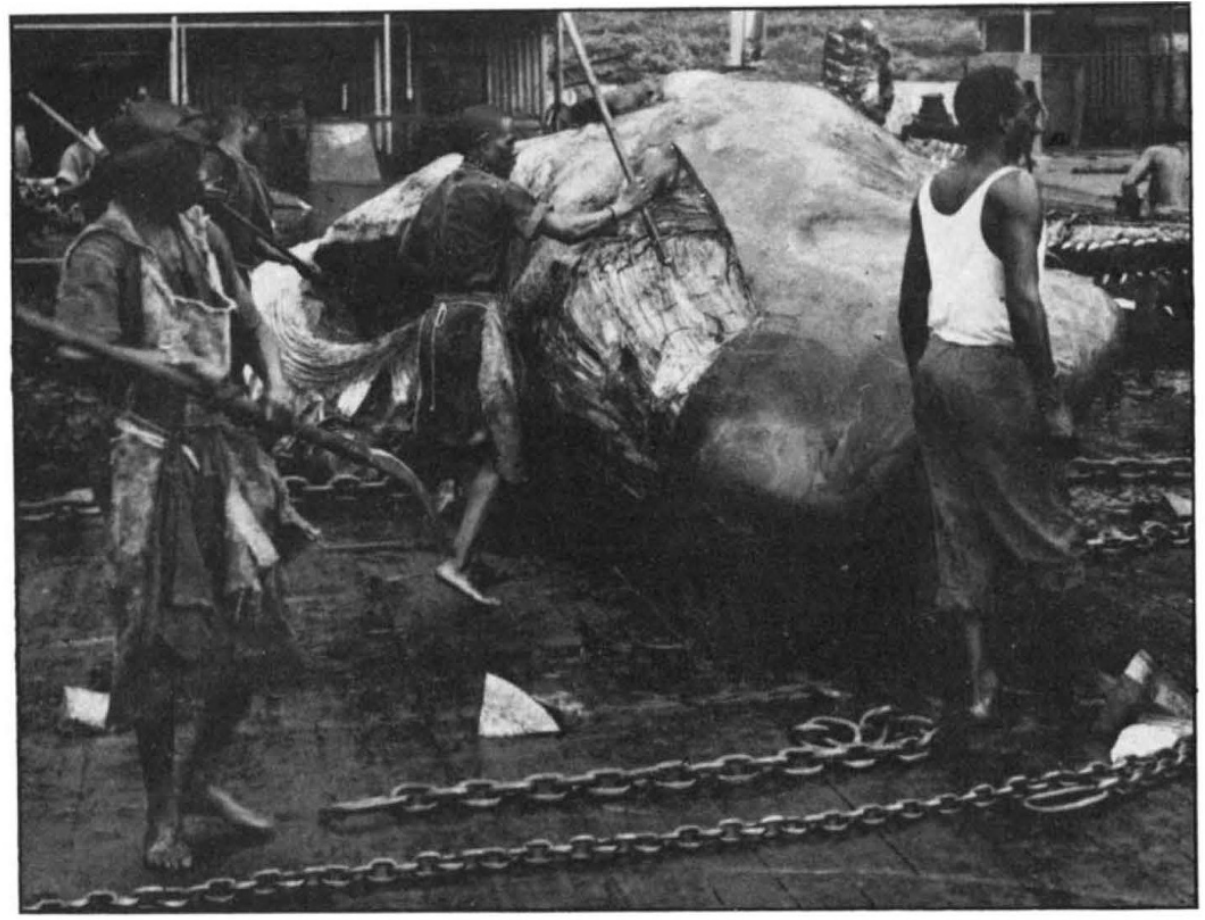

\section{Whales: conserving a resource}

In spite of an expression of 'cautious optimism' after this year's meeting of the International Whaling Commission, and a recent Nature article which was optimistic about whale populations, there are still fears that all is not well in the whaling industry. Dr Sidney Holt, Director of the International Ocean Institute in Malta highlights some of the prohlems still confronting whale conservation and management.

AT the end of the meeting of the International Whaling Commission last June, a number of interested nongovernmental organisations put out a statement expressing "cautious optimism" regarding the results achieved there. Dr Ray Gambell has been commendably prompt in bringing these results to the attention of readers of Nature (August 9, 1974). We who participated in the IWC meeting must agree that the adoption of what Dr Gambell calls the "amended moratorium proposal" was a significant advance towards rational management of whaling. This is, however, no time for complacency by scientists, governments or the interested public, and Dr Gambell's article is not, I think, sufficiently critical of the present state of whale population assessments. It is not insignificant that Dr Gambell illustrated his article with hypothetical diagrams rather than with an example. "The exact forms of the relationships ... are not known for certain ..." is far too mild an expression of real doubts. A number of weaknesses in present calculations are well known to members of the IWC's Scientific Committee, although there seems to be less divergence of opinion within the Committee than in the past. I have drawn the Committee's attention to other deficiencies identified by a special working party of the FAO Advisory Committee on Marine Resources Research with which Dr Gambell is also associated. I will not reiterate these but merely observe that although they do not all point in the same direction, their general sense is that the IWC's Scientific Advisers may still be erring on the side of optimism. Here, however, I wish to draw attention to some specific points raised by Dr Gambell's article. There is a slip in his exposition of the simple theory of density-dependent rates. The natural mortality rate might "fall as whales are caught", but not because they "are caught before they have a chance to die naturally". In all models used the mortality rates, both "natural" and "due to whaling" are, by definition, independent exponential coefficients, not absolute quantities.

Then there are two significant errors in the table of present sustainable yields (SY) given. SY for female sperm whales in the Southern hemisphere is 1,800 , not 4,500 . The latter figure is the calculated maximum sustainable yield of females which could be obtained if their numbers were reduced. This would, however, be, in part at least, at the expense of the catch of males, which are far more important because they are both bigger and more numerous. The high quota of 5,000 is designed to reduce the number of females quite drastically -an act of doubtful wisdom. The SY of 1,700 given in the table for North Pacific female sperm whales is correct (insofar as any of these calculated values are "correct"); the corresponding MSY is 3,400 which is considerably less than the permitted quota of 4,000 .

The second error concerns the Minke whale. The stated present SY in the Antarctic of $7,000-12,000$ is an estimate of the maximum SY; the Minke is said to be very lightly exploited at present and its present SY is certainly much lower than 7,000. That, however, is not the main point. There are practically no hard facts about the population of this species. As the report says, "The Scientific Committee was unable to reach any conclusion ... for Minke whales," and it " advised caution in setting catch limits . . "By analogy with other species, which are rather better known, the Scientific Committee proposed a quota of 5,000 , as they did last year. This was not acceptable to Japan and the Soviet Union, who share about equally the present catches, and the 7,000 quota was a compromise; it cannot be described as the outcome of "rational policy". The case of the Minke is important because it has suddenly become, in the last two seasons, an important item in the catches of baleen whales by the pelagic expeditions. From being negligible in the 1968-69 season, it jumped to $12 \%$ by weight in 1969-70, and grew to nearly one-third of the total of 190,000 tons taken in the 1973-74 season. The stepping up of the Minke catch is one more step (the last?) in the process of maintaining the profitability of Antarctic whaling by successively exploiting smaller and smaller species of whalesthe earlier steps were from blue whales to fin whales to sei whales. That this process is now regulated-but hardly restrained-under a quota system does not mean that it is "rational", that it will ensure survival of a viable population of Minke whales, or that it will necessarily ensure the possibility of high sustained yields from that species in the long term. Judging from past performance, there may be a lapse of up to ten years before the member countries of the IWC are able to agree to act on important advice from its Scientific Committee. Some of the international commissions which regulate the sea fisheries have a similar concept of time and urgency but biologically fishes are more resilient than marine mammals.

It is also a general feature of the history of whaling that by the time there is widespread concern about the survival of one species the industry has already moved to heavy exploitation of another. Thus, while in the past decade or so, "conservation minded" organisa- 
tions have become aware of what was happening to the blue whale and, lately, the fin whale, the sperm whale has become by far the most important species both in the Antarctic and in world catches. It now accounts for over $40 \%$ by weight of the total catch of all species of whales. Its monetary value is not quite so high because, although sperm oil, the main product, fetches higher prices than, and has different uses from, the baleen oil, the sperm whale meat is not suitable for human consumption. (This means that the argument used by the Japan Whaling Association for continued intensive whaling because whale meat is an important ingredient of the diet of school children and poorer people is not applicable to the sperm whaling industry.) Scientific assessment of sperm whale stocks is especially difficult because of particular features of their biology and of the industry based on them. The IWC Scientific Committee believes that the level of catch of males is at about their maximum sustainable yield in numbers. It is said that a convenient aspect of sperm whaling is that the males are bigger than the females, there is much geographical segregation of the sexes, and the social behaviour (including a "harem" structure) are such that a large "surplus" of males can readily be caught. I find it difficult to reconcile this with the decision to reduce the size limit for females "in order to bring the sexes into better balance". Sperm whales are especially important to the Soviet Union, whose whalers now regularly take over half the world total, yet the USSR delegation to the IWC appeared to be having second thoughts about that decision.

But there is a further problem. Whereas males caught twenty years ago averaged 45 tons each in weight, now they average only 28 tons. The size of females has also declined (though not relatively so much because they have, until now, been less intensively exploited). In fact, the average size of all the large species of baleen whales also has declined over the period in which each of them has been intensively exploited. This means that management for maximum sustainable yield in weight (and hence maximum value of product) requires rather different criteria for management than are at present used. This is particularly true for sperm whales, but for all species the desirable level of population is higher than is needed to maximise the yield in numbers. This should please the whaling industry as well as 'conservationists'. The latter group wants survival of species and of stocks to be assured and for the whales to continue to play an important role in marine ecosystems. The former finds that ex- ploiting stocks when they are at high levels of abundance is much more profitable than when the stocks are depleted. This is as true under management for sustained yields as it is for unrestrained whaling. The only trouble is that to maximise the weight yield from an overexploited stock, one has to agree to more stringent immediate conservation measures, and wait longer for their beneficial effects.

Incidentally, the fact that a substantial part of the sperm whale catch is by ships flying flags of non-member countries of the IWC, that it is not unknown for industries to operate under a convenient flag, especially when international regulations become burdensome, and that some countries refrain from joining the IWC for political rather than technical reasons, suggest that it is desirable for the United Nations Environment Programme and other UN Agencies with wide membership to retain their in-

\section{To maximise the weight yield} from an overexploited stock one has to agree to more stringent immediate conservation measures and wait longer for their beneficial effects. . .

terest in whaling, while continuing to assist and support the IWC.

Dr Gambell's article gives the impression that defining MSY in terms of weight involves a new concept requiring special study. On the contrary, apart from being practically universal in fishery management, the MSY (weight) criterion was introduced to the IWC over 13 years ago, at the same time as the attainment of sustainable yields in numerical terms was first seriously discussed there. The necessary data are available, as are the mathematical models; it is simply a question of feeding one into the other. The whaling industry has naturally always measured its success by the weight and price of its products, not by the number of whales caught, and it is time the scientific advisers to IWC did the same.

Calculations of recent and expected yields in weight show that if the 197475 quotas for pelagic whaling in the Southern hemisphere are reached (as the 1973-74 ones were not) the catch of all species next season may reach 380 thousand tons, 2 or $3 \%$ more than in 1973-74. This pelagic industry is still important; in recent years it has accounted for $60 \%$ of the world catch of the larger whale species.

Dr Gambell is right in saying that more research is needed-and at prac- tically every level, including critical study of the mathematical models currently used, and investigations of the ecological interactions between the species of whales, and between them and other marine organisms on which they feed or with which they compete. In this connection it should be noted that the suggestion to which Dr Gambell refers in his opening paragraphand it was no more than a hypothetical suggestion-that catching some species may help the recovery of others, is based solely on the fact that they overlap in the composition of their diet. No quantitative evidence whatever has yet been presented to support it. In fact, a number of important assumptions that are regularly made have not yet been tested; these include the assumptions that each whale population is in a steady state before man starts exploiting it, and that his effect on it is merely reversed if and when his predation is eased.

Meanwhile, the world catch of whales is, despite the depletion of the resource and because of the rising prices of meat and oil, still worth about $£ 80$ million annually. It could, if stocks were permitted to recover, be worth many times that at present prices-and even more with the expected relative rise in the prices of animal protein in the coming years. Against this we recognise that Dr Gambell and his few colleagues work with very limited facilities and funds, as do similar groups in other countries. Although no whaling expeditions now fly the British flag, the United Kingdom is stil a considerable importer of some whale products, and presumably retains a long term interest in resources which could once again yield $10 \%$ or more of the total value of the world marine harvest, and practically all from the area of ocean which will be beyond national jurisdictions even if the United Nations Conference on the Law of the Sea agrees eventually to an "economic resource zone" 200 miles wide. Now is the time to make substantially greater means available for research on cetaceans and for international management of them. It would be folly, as some seem to wish, for research to be cut back because of the decline of an important industry, which is a result of our past failure to protect the resource base. At the same time it must be hoped that research on the use of the other living resources of the open ocean, such as the Antarctic krill and the deep water cephalopods, will not be left entirely to the two nations remaining in the business of pelagic whaling. If this is too big an enterprise for other maritime countries, should we not be thinking of a substantial international programme of research and development? 